ciclos. No grupo B houve um maior percentual de formas severas. A diarréia foi manifestação digestiva pouco freqüente, comprometendo apenas 6 ciclos e sempre de forma leve.

Houve redução nos niveis da fração de ejeção ventricular esquerda (FEVE) em 90\% dos casos, sendo $80 \%$ no grupo A e $100 \%$ no grupo B. Em apenas 8 casos (13\%) a FEVE esteve abaixo do normal, sendo 2 (6\%) no grupo A e 6 (20\%) no grupo B. Nas outras pacientes as reduções da FEVE foram menores que 20\%. Houve alterações inespecíficas no eletrocardiograma (ECG). As mais freqüentes foram alterações da repolarização ventricular, taquicardia e extra-sístoles. As alterações da FEVE e ECG foram mais freqüentes e intensas no grupo B, porém não tiveram manifestações clínicas.

A resposta clínica objetiva (resposta completa e resposta parcial) nos grupos A e B foi 93\% e 96\%, respectivamente. Os resultados foram similares, porém no grupo B houve um percentual maior de respostas clínicas completas.

Avaliou-se a doença residual no sítio primário e nos linfonodos axilares. No grupo A houve 4 (13\%) casos de reposta anatomopatológica completa, 12 (40\%) de tumor residual microscópico e 14 (47\%) de tumor macroscópico. No grupo B ocorreram 10 (33\%) casos de resposta anatomopatológica completa, 7 (23\%) de tumor residual microscópico e 13 (44\%) de tumor macroscópico.

Concluiu-se que a quimioterapia primária proporcionou resposta clínica e anatomopatológica maior no grupo com intensificação de dose. A toxicidade, tolerável e reversível, foi mais acentuada no grupo de altas doses.

Palavras-chave: Mama: câncer. Quimioterapia. Quimioterapia neoadjuvante.

\title{
Influência da Tibolona e do Exercício Físico Aeróbio sobre a Antropometria e o Perfil Lipídico na Menopausa
}

Dissertação de Mestrado, apresentada ao Departamento de Ginecologia e Obstetrícia da Faculdade de Medicina de Botucatu da Universidade, Estadual Paulista, em 14/11/97.

Autor: Eliana Aguiar Petri Nahás

Orientador: Prof. Dra. Anagloria Pontes

Na menopausa há aumento do depósito de gordura abdominal influenciado pelo hipoestrogenismo e hiperandrogenismo relativo. A obesidade androgênica é metabolicamente diferente da ginecóide, porque apresenta maiores taxas de lipólise, com conseqüentes alterações negativas no perfil lipídico e aumento do risco para doença cardiovascular (DCV). O objetivo deste estudo foi avaliar as repercussões sobre a antropometria e perfil lipídico da mulher em menopausa, submetidas ao exercício físico aeróbio e à tibolona. Dezenove mulheres menopausadas foram divididas em 2 grupos: obesas $(n=12)$ e não-obesas $(n=7)$ e seguidas por 18 meses. As pacientes realizaram exercício físico aeróbio isolado, por 6 meses, com duração de 75 minutos, em três períodos semanais. O exercício foi associado à tibolona, na dose oral de 2,5 mg/dia, durante 12 meses. A antropometria foi avaliada pelo índice de massa corpórea (IMC), pela relação cintura-quadril (RCQ) e pela medida de pregas cutâneas. Considerou-se obesidade o $\mathrm{IMC}^{3} 30 \mathrm{~kg} / \mathrm{m}^{2}$ e a distribuição de gordura androgênica, quando $\mathrm{RCQ}>0,80$. A porcentagem de gordura corporal, obtida pelo somatório das medidas de pregas cutâneas, foi considerada elevada, acima de 30\%. Avaliou-se no perfil lipídico o colesterol total, HDL, LDL, VLDL e triglicerídeos. Inicialmente, observou-se o colesterol total e LDL elevados, com HDL, VLDL e triglicerídeos normais em todas as pacientes. Independentemente do IMC e da porcentagem de gordura corporal, as pacientes apresentavam RCQ androgênica. Com exercício físico aeróbio isolado, ocorreu redução da porcentagem de gordura corporal e queda do colesterol total, LDL, VLDL e dos triglicerídeos, ao passo que o HDL, o IMC e a RCQ não se alteraram. Quando associado à tibolona não se observou ganho de peso ou de gordura corporal, mas ocorreu diminuição da RCQ. Os valores de colesterol total e LDL mantiveram-se inalterados, ao passo que houve queda acentuada do HDL com 6 meses da tibolona, retornando seus valores próximos aos basais no final dos 12 meses. Os triglicerídeos e VLDL continuaram em decréscimo significativo até o final do estudo. Observou-se homogeneidade das respostas entre obesas e não-obesas quanto ao perfil lipídico e parâmetros antropométricos. O exercício físico contribuiu para redução da porcentagem de gordura corporal e dos níveis do colesterol total e LDL e, a tibolona para diminuição da RCQ e dos triglicerídeos e VLDL. Estes resultados sugerem que o exercício físico aeróbio e a tibolona podem ter efeitos benéficos e complementares sobre a antropometria e o perfil lipídico, na mulher em menopausa.

Palavras-chave: Menopausa. Perfil lipídico. Exercício físico. Terapia de reposição hormonal. 